\title{
Hubungan Gejala Klinis Dengan Tekanan Intraventrikuler Pada Hidrosefalus Akut
}

\author{
Donny Argie, Muhammad Zafrullah Arifin, Achmad Adam, \\ Akhmad Imron, Mirna Sobana, Agung Budi Sutiono
}

\begin{abstract}
Abstrak
Penelitian tentang gejala klinis atau tekanan intrakranial pasien pediatrik yang menderita hidrosefalus akut telah banyak dilakukan, tetapi penelitian yang menghubungkan antara gejala klinis dan tekanan intrakranial pasien pediatrik yang menderita hidrosefalus akut belum banyak dilakukan. Berdasarkan hal tersebut, dilakukan penelitian ini untuk mengetahui hubungan antara gejala klinis dengan tekanan intraventrikuler pada pasien pediatrik penderita hidrosefalus akut.

Penelitian ini adalah penelitian prospektif analitik, dimana data diambil dari tanggal 1 Januari 2010 sampai dengan 17 Agustus 2013 di Departemen/SMF Ilmu Bedah Saraf Fakultas Kedokteran Universitas Padjadjaran/RSUP Dr. Hasan Sadikin Bandung.

Dari hasil penelitian didapatkan jumlah sampel pasien hidrosefalus akut, sebanyak 27 laki-laki (53\%) dan 24 perempuan (47\%). Penyebab hidrosefalus akut pada penelitian ini adalah neoplasma yaitu sebanyak 24 kasus (47\%), dan infeksi 23 kasus (45\%). Hasil uji secara statistik menunjukkan bahwa gejala klinis muntah dan penurunan kesadaran memiliki nilai yang bermakna dengan $p<0.05$ sedangkan nyeri kepala memiliki nilai yang tidak bermakna terhadap peningkatan tekanan intraventrikuler dengan nilai $p>0.05$.

Gejala klinis muntah dan penurunan kesadaran mempunyai hubungan dengan tekanan tinggi intrakranial sehingga dapat digunakan sebagai deteksi dini pada pasien pediatrik penderita hidrosefalus akut yang disebabkan oleh neoplasma maupun infeksi. (J I Bedah Indones. 2014.43:43-47)
\end{abstract}

Kata kunci: Gejala Klinis, Tekanan Intrakranial, Hidrosefalus Akut

\section{Pendahuluan}

Selama ini penatalaksanaan pada pasien pediatrik yang menderita hidrosefalus dihadapkan pada masalah kompleks. Dalam bidang bedah saraf pediatrik, hidrosefalus merupakan kasus yang dominan, sebanyak 40\% - 50\% memerlukan intervensi bedah. Data yang didapatkan berdasarkan survei cross-sectional pada tahun 1997, 2000, dan 2003 di Amerika, mengungkapkan 40.000 kasus hidrosefalus pada pediatrik dan 1000 kasus memerlukan tindakan bedah pintas cairan serebrospinalis. ${ }^{1-5}$

Penelitian tentang gejala klinis atau tekanan intrakranial pasien pediatrik penderita hidrosefalus akut telah banyak dilakukan, tetapi penelitian yang menghubungkan antara gejala klinis dan tekanan

\footnotetext{
Alamat Korespondensi:

Agung Budi Sutiono

Departemen Ilmu Bedah Saraf

Fakultas Kedokteran Universitas Padjadjaran

RSUP dr. Hasan Sadikin

Email: agungbudis@gmail.com
}

intrakranial pasien pediatrik penderita hidrosefalus akut yang disebabkan oleh neoplasma dan infeksi belum banyak dilakukan ${ }^{6-10}$. Oleh karena itu dilakukan penelitian yang bertujuan untuk mengetahui hubungan antara gejala klinis pasien pediatrik penderita hidrosefalus akut yang disebabkan oleh neoplasma dan infeksi dikaitkan dengan tekanan intrakranial. Diharapkan gejala klinis tersebut bisa dijadikan sebagai petanda awal untuk melakukan tindakan bedah pintas diversi cairan serebrospinal. ${ }^{11-17}$

\section{Metodologi}

Sebanyak 51 pasien pediatrik dengan hidrosefalus akut yang disebabkan oleh neoplasma dan infeksi yang dirawat di Bagian Bedah Saraf RSUP Dr. Hasan Sadikin Bandung antara bulan Januari 2010 hingga Agustus 2013 telah diikutsertakan dalam penelitian ini.

Penelitian ini merupakan penelitian prospektif analitik dengan metode cross-sectional dengan melakukan 
pengumpulan data gejala klinis pada pasien pediatrik penderita hidrosefalus akut yang disebabkan oleh neoplasma dan infeksi yang dirawat di Bagian Bedah Saraf RSUP Dr. Hasan Sadikin Bandung, data nilai tekanan intraventrikuler diukur dengan sambungan manometer air sebelum dilakukan penyambungan shunt abdominal, atau ekstra ventrikuler drainase, atau subkutan drainase pada saat dilakukan tindakan operasi bedah pintas, seperti terlihat pada gambaran skematis pengukuran tekanan intraventrikuler pada gambar 1.

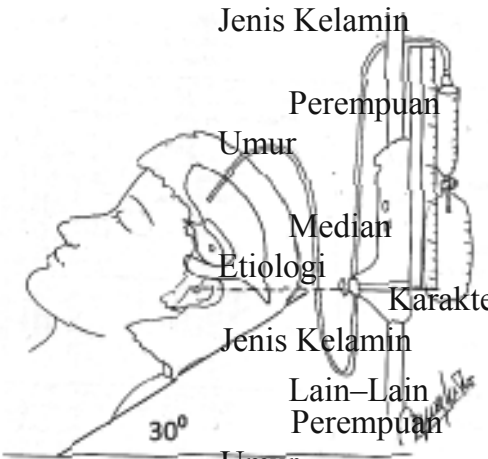

Gambar 1. Pengukuran Tekanan Intraventrikuler
Untuk menguji hubungan antara dua variabel, digunakan uji chi square. Analisis ini menggunakan software SPSS (Statistic Product Service Solution) versi 17.0. Kemaknaan ditentukan berdasar nilai $\mathrm{p} \leq 0,05$.

\section{Hasil}

Sebagian besar pasien hidrosefalus akut pada penelitian ini adalah laki-laki yaitu 27 orang (53\%), sedang kan perempuan 24 orang (47\%) dengan umur ratarata 7 tahun dan nilai median umur 6 tahun. Etiologi hidrosefalus akut pada penelitian ini adalah neoplasma yaitu sebanyak 24 kasus (47\%), dan infeksi 23 kasus (45\%); sebagaimana ditunjukkan pada tabel 1. Pada tabel 2 ditunjukkan pasien yang mempunyai tekanan intraventrikuler $>15 \mathrm{mmHg}$, $9(33 \%)$ pasien laki-laki dan $10(42 \%)$ pasien perempuan. Hasil uji statistik menunjukkan bahwa jenis kelamin tidak berhubungan dengan peningkatan tekanan intraventrikuler $(\mathrm{p}>0.05)$.

Tabel 1. Karakteristik Subjek Penelitian

\begin{tabular}{ll}
\hline \multicolumn{1}{c}{ Karakteristik } & $\mathrm{N}=51(\%)$ \\
\hline Jenis Kelamin & \\
$-\quad$ Laki-Laki & $27(53)$ \\
$-\quad$ Perempuan & $24(47)$ \\
\hline Umur & 7 tahun \\
$-\quad$ Rata-Rata & 6 tahun \\
$-\quad$ Median & \\
\hline Etiologi & $24(47)$ \\
$-\quad$ Neoplasma & $23(45)$ \\
$-\quad$ Infeksi & $4(8)$ \\
$-\quad$ Lain-Lain &
\end{tabular}

Tabel 2. Hubungan Antara Jenis Kelamin dan Tekanan Intraventrikuler

\begin{tabular}{lccccc}
\hline \multirow{2}{*}{ Jenis Kelamin } & \multicolumn{3}{c}{ Tekanan $(\mathrm{mmHg})$} & \multirow{2}{*}{ Total } & P value \\
\cline { 2 - 4 } & $7-10$ & $11-15$ & $>15$ & & \\
\hline Laki-Laki & 6 & 12 & 9 & 27 & 0.529 \\
Perempuan & 7 & 7 & 10 & 24 & \\
Total & 13 & 19 & 19 & 51 & \\
\hline
\end{tabular}

Tabel 3. Hubungan Antara Nyeri Kepala dan Tekanan Intraventrikuler

\begin{tabular}{|c|c|c|c|c|c|}
\hline \multirow[t]{2}{*}{ Nyeri kepala } & \multicolumn{3}{|c|}{ Tekanan(mmHg) } & \multirow{2}{*}{ Total } & \multirow{2}{*}{$P$ value } \\
\hline & $7-10$ & $11-15$ & $>15$ & & \\
\hline Ada & 9 & 13 & 14 & 36 & \\
\hline Tidak ada & 4 & 6 & 5 & 15 & 0.931 \\
\hline Total & 13 & 19 & 19 & 51 & \\
\hline
\end{tabular}


Tabel 4. Hubungan Antara Muntah dan Tekanan Intraventrikuler

\begin{tabular}{lccccc}
\hline \multirow{2}{*}{ Muntah } & \multicolumn{3}{c}{ Tekanan $(\mathrm{mmHg})$} & \multirow{2}{*}{ Total } & \multirow{2}{*}{ Pvalue } \\
\cline { 2 - 4 } & $7-10$ & $11-15$ & $>15$ & 13 & \\
\hline Ada & 10 & 2 & 1 & 38 & 0.000 \\
Tidak ada & 3 & 17 & 18 & 51 & \\
Total & 13 & 19 & 19 & 51 \\
\hline
\end{tabular}

Tabel 5. HubunganAntara Penurunan Kesadaran dan Tekanan Intraventrikuler

\begin{tabular}{lccccc}
\hline \multirow{2}{*}{$\begin{array}{c}\text { Penurunan } \\
\text { kesadaran }\end{array}$} & \multicolumn{3}{c}{ Tekanan(mmH) } & Total & P value \\
\cline { 2 - 4 } & $7-10$ & $11-15$ & $>15$ & & 21 \\
\hline Ada & 5 & 13 & 3 & 30 & 0.004 \\
Tidak ada & 8 & 6 & 16 & 51 & \\
Total & 13 & 19 & 19 & \\
\hline
\end{tabular}

Dari 36 pasien, 14(39\%) pasien menunjukkan tekanan intraventrikuler $>15 \mathrm{mmHg}, 13(36 \%)$ pasien menunjukkan tekanan intraventrikuler $11-15 \mathrm{mmHg}$, dan $9(25 \%)$ pasien menunjukkan tekanan intraventrikuler 7-10 mmHg (tabel 3). Pengujian statistik menunjukkan bahwa nyeri kepala tidak memiliki hubungan signifikan dengan peningkatan tekanan intraventrikuler $(\mathrm{p}>0,05)$.

Pada tabel 4 ditunjukkan bahwa dari 13(26\%) pasien disertai keluhan muntah, ditemukan terbanyak pada pasien dengan tekanan intraventrikuler 7-10 mmHg sebanyak 10 orang, 2 pasien dengan tekanan intrakranial 11-15 mmHg dan 1 pasien dengan tekanan $>15$ mmHg. Sedangkan pasien yang tidak disertai muntah ditemukan sebanyak 38 (74\%) pasien, 18 pasien mempunyai tekanan intraventrikuler $>15 \mathrm{mmHg}, 17$ pasien mempunyai tekanan intraventrikuler 11-15 $\mathrm{mmHg}$, dan 3 pasien mempunyai tekanan intraventrikuler 7-10 mmHg. Uji statistik menunjukkan bahwa muntah memiliki hubungan yang signifikan dengan peningkatan tekanan intraventrikuler $(\mathrm{p}<0,05)$.

Pada tabel 5 ditunjukkan bahwa sebagian besar pasien dengan keluhan penurunan kesadaran, ditemukan pada 13 pasien dengan tekanan intraventrikuler 11-15 $\mathrm{mmHg}$, sedangkan sebagian besar pasien yang tidak mempunyai gejala penurunan kesadaran, ditemukan sebanyak 16 pasien mempunyai tekanan intraventrikuler $>15 \mathrm{mmHg}$. Uji statistik menunjukkan bahwa penurunan kesadaran memiliki hubungan signifikan dengan peningkatan tekanan intraventrikuler $(\mathrm{p}<0,05)$.

\section{Diskusi}

Penelitian mengenai gejala klinis atau tekanan intrakranial pada pasien pediatrik penderita hidrosefalus akut telah banyak dilakukan, tetapi penelitian yang menghubungkan antara gejala klinis dan tekanan intraventrikuler pada pasien pediatrik penderita hidrosefalus akut belum banyak dilakukan. ${ }^{11-15}$

Michael mendefinisikan bahwa yang disebut anakanak adalah kelompok usia lebih dari 2 tahun. ${ }^{16-24}$ Bagian Ilmu Kesehatan Anak Fakultas Kedokteran Universitas Padjadjaran mengelompokkan anak-anak pada usia 1-14 tahun. Pada penelitian ini, peneliti memakai acuan kelompok umur 2-14 tahun dengan alasan penutupan fontanel dan sutura kepala berakhir pada usia 2 tahun. Karakteristik subjek penelitian pada penelitian ini setelah mempertimbangkan kriteria inklusi dan eksklusi adalah pasien laki-laki sebanyak 27 orang (53\%), sedangkan perempuan sebanyak 24 orang $(47 \%)$, rerata umur pasien hidrosefalus akut adalah 7 tahun dengan standar deviasi 3,39, dan median 6 tahun.

Hdeib mengatakan bahwa terdapat perbedaan etiologi hidrosefalus menurut usia pada pasien anakanak; neoplasma dan trauma merupakan penyebab ter sering hidrosefalus pada anak-anak. ${ }^{25-26}$ Kestle mengatakan bahwa neoplasma, trauma, dan infeksi adalah penyebab tersering pada anak-anak. ${ }^{1}$ Pada penelitian ini, dari 51 pasien hidrosefalus pada anak-anak, sebagian besar disebabkan oleh neoplasma sebanyak 24(47\%) pasien dan infeksi sebanyak 23(45\%) pasien.

Wang dan Avellino membagi gejala klinis pasien 
hidrosefalus berdasarkan kelompok usia. Pada anakanak, gejala yang sering timbul adalah nyeri kepala, muntah dan penurunan kesadaran. ${ }^{8}$ Anderson mengatakan bahwa gejala klinis pasien hidrosefalus pada anak-anak adalah iritabilitas (27\%), muntah (19\%), dan nyeri kepala $(18 \%) .{ }^{27}$

Pada penelitian ini, gejala klinis yang sering timbul pada pasien anak-anak penderita hidrosefalus akut adalah nyeri kepala, penurunan kesadaran, dan muntah. Perbedaan ini kemungkinan besar disebabkan karena peneliti tidak menemukan gejala tunggal pada pasien anak-anak penderita hidrosefalus akut pada saat pengumpulan data.

Berbeda dengan penelitian sebelumnya, penelitian ini selain mengumpulkan data mengenai gejala klinis yang timbul pada pasien anak-anak penderita hidrosefalus akut juga menghubungkan dengan tekanan intraventrikuler. Hasil uji secara statistik pada penelitian ini menunjukkan gejala klinis muntah dan penurunan kesadaran mendapatkan nilai $p$ value $<0,05$ yang artinya gejala klinis muntah dan penurunan kesadaran mempunyai hubungan dengan tekanan tinggi intraventrikuler pada pasien pediatrik yang menderita hidrosefalus akut.

Jika dilihat dari hubungan antara gejala muntah dengan tekanan intrakranial, tampak bahwa pada fase awal peningkatan intrakranial, pasien cenderung terjadi muntah dan setelah tekanan intrakranial cenderung meningkat maka gejala muntah tersebut cenderung menghilang. Hal ini membuktikan bahwa jika terjadi keluhan gejala muntah pada pasien dengan hidrosefalus maka ini merupakan petanda bahwa kondisi tersebut merupakan awal dari munculnya peningkatan tekanan intrakranial. Justru saat muntah tersebut berkurang, maka dikhawatirkan bahwa tekanan intrakranial tersebut sudah sangat meningkat. Fenomena menarik juga terjadi dimana penurunan kesadaran ternyata lebih banyak terjadi pada pasien dengan rata-rata tekanan intrakranial 11-15 mmHg, sehingga pada fase ini kemungkinan tekanan tersebut akan mempengaruhi pusat kesadaran, dan saat tekanan intrakranial tersebut melewati $15 \mathrm{mmHg}$ maka hal tesebut sudah jarang menimbulkan gejala penurunan kesadaran. Dari hasil inilah, intervensi bedah pintas untuk diversi cairan serebropinal harus segera di- lakukan. Dengan kata lain, jika pasien hidrosefalus memiliki gejala muntah maka alangkah baiknya untuk segera dilakukan intervensi, dan jika sudah mulai terjadi penurunan kesadaran maka tekanan intrakranial tersebut sudah lebih tinggi lagi. Adapun tidak adanya gejala penurunan kesadaran pada pasien dengan tekanan intrakranial $>15 \mathrm{mmHg}$ kemungkinan disebabkan oleh mekanisme kompensasi pada pasien dengan hidrosefalus kongenital dimana fontanel dan sutura pada anak belum menutup dengan sempurna. Sedangkan untuk neoplasma penurunan kesadaran ini dapat muncul lebih awal.

\section{Kesimpulan}

Terdapat hubungan positif antara gejala klinis dengan peningkatan tekanan intraventrikuler pada hidrosefalus akut. Gejala klinis yang tampak pada pasien pediatrik penderita hidrosefalus akut adalah muntah dan penurunan kesadaran. Dimana gejala muntah ini muncul pada fase awal peningkatan tekanan intrakranial dilanjutkan dengan apabila terdapat penurunan kesadaran maka hal ini menunjukan bahwa tekanan tersebut lebih meningkat lagi. Dengan demikian hasil penelitian ini dapat dipakai sebagai deteksi dini untuk penatalaksanaan pasien pediatrik penderita hidrosefalus akut.

\section{Daftar Pustaka}

1. Kestle John RW. Hydrocephalus in Children: Approach to the Patient. Neurological Surgery. Youmans; Vol II; section VII; part 4; ch.186. Philadelphia. Elsevier Saunders. 2011;1982-86

2. Mori K. CT Diagnosis of Abnormal Head Size \& Hydrocephalus dalam Anomalies of the Central Nervous System. Neuroradilology and Neurosurgery; ch.3,4. Philadelphia. Thieme. 1985;7-17.

3. Rekate HL, Cohen R. Pathophysiology, Diagnosis, and Clinical Features of Hydrocephalus in Infant and Children, The Practice of Neurosurgery; William and Wilkins; Vol I; part VIII; section 1. New York. McGraw Hill. 1987; 2689-99.

4. Raimondi AJ. Hydrocephalus. Pediatric Neurosurgery: Theoretic Principles Art of Surgical Techniques. New York. Spinger-Verlag. 1987;453-92.

5. Greenberg MS. Hydrocephalus. Handbook of Neurosurgery; Edisi ke-7. New York. Thieme. 2010;307-337.

6. Rosner MJ. Techniques for Intracranial Pressure Monitorin, 
The Practice of Neurosurgery; Williams \& Wilkins; Vol I. New York. McGraw Hill. 1998; 95-118.

7. Milhorat, TH. Hydrocephalus: Pathophysiology and Clinical Features. Wilkins \& Setti. Neurosurgery; edisi ke-2, Vol III. New York. Thieme. 1996;3625-30.

8. Paul P Wang, Avellino AM. Hydrocephalus in children, Principles of Neurosurgery; Setti S Rengachary; Edisi ke-2. San Fransisco. McGraw Hill. 2005;137-40.

9. Gunawan S. Penghitungan Skor CT Scan Sebagai Penentu Tekanan Intrakranial Pada Penderita Hidrosefalus Akut [Tesis]. Bandung: Universitas Padjadjaran. 2009.

10. Rosner MJ. Techiques for Intracranial Pressure Monitoring. The Practice of Neurosurgery; Williams \& Wilkins; Vol I. New York. McGraw Hill. 1998;95-118.

11. Langfitt TW. Increased Intracranial Pressure and Cerebral Circulation. Neurological Surgery; A Comprehensive Reference Guide to the Diagnosis and Management of Neurosurgical Problems; J.R. Youman; Edisi ke-2, Vol I, chapter 24. New York. Thieme. 1992; 846-928.

12. John RW. Communicating Hydrocephalus. Hunt Batjer \& M. Loftus. Textbook of Neurological Surgery, Priciples and Practice; Vol I. New York. Lippincott William \& Wilkins. 2003;871-5.

13. Flemming Gjerris, Svend Eric Borgensen. Pathophysiology of Cerebrospinal Fluid Circulation; Neurosurgery; The Scientific Basis of Clinical Practice; Alan Crockard; Edisi ke-3. Vol I; chapter 12. New York. Blackwell Science. 2000;14759.

14. Joseph HP. Hydrocephalus: Treatment. Wilkins \& Setti. Neurosurgery; Edisi ke-2, Vol III. Philadelpia. McGraw Hill.1996;3633-43.

15. Brosche TM.. Intracranial Pressure and Cerebral Perfusion Pressure Range; AACN Advanced Critical Care Nursing. St Louis. Elsevier Saunders. 2011;25-37.

16. Rekate HL. Treatment of Hydrocephalus. Pediatric Neurosurgery; Surgery of The Developing Nervous System. William R. Cheek, MD; Edisi ke-3; Chapter 13. Pennsylvania. Saunders.1994;202-18.

17. Unterberg AW. Brain Oedem; Neurosurgery; The Scientific Basis of Clinical Practice; Alan Crockard; Edisi ke-3. Vol I; Ch 29. New York. Blackwell Science. 2000;410-28.

18. Reulen HJ.. Brain Edema; Act Neurochirurgica Supplementum 51; Edisi ke-8. New York. Spinger-Verlag Wien.1990;351-54.

19. Adams RD, Maurice Victor. Disturbances of Cerebrospinal Fluid Circulation, Icluding Hydrocephalus and Meningeal Reaction; Principles of Neurosurgery; Edisi ke-5, Part IV. New York. McGraw Hill.1993;539-51.
20. Davis DO, Kobrine A. Computed Tomography. Neurological Surgery; A Comprehensive Reference Guide to The Diagnosis and Management of Neurosurgical Problems; Vol I, Chapter 5. Baltimore. Mosbi. 1998;111-40.

21. Lemay M. Ventricular Differences between Hydrostatic Hydrocephalus and Hydrocephalus Ex Vacuo by Computed Tomography. J Neuroradiol. Spinger-Verlag.1978; 17: 191-195

22. May Lindy. Paediatric Neurosurgery. A Handbook for The Multidisciplinary Team; Chapter 1. Whurr Publishers Ltd.2001;1-25.

23. Setiawan N. Penentuan Ukuran Sampel Memakai Rumus Slovin dan Tabel Krejcie-Morgan: Telaah Konsep dan Aplikasinya. Diskusi Ilmiah Jurusan Sosial Ekonomi Fakultas Peternakan Unpad, 2007.

24. Michael J. Neurological Examination of the Newborn, Infant, and Child; Principles and Practice of Pediatric Neurosurgery; Section I. Thieme Medical Publishers, Inc. 2008;31-42. 25. Alia Hdeib. Hydrocephalus in Children and Adult; Principles of Neurological Surgery; Ch. 6. Elsevier Saunders. 2011;116-138.

26. Morgan B. Procedure for Measurement of Intracranial Pressure Using Fluid Filled System. 2013. Avaliable in website: http://www.lhsc.on.ca/Health_Professionals/ CCTC/procedures/ICP_Fluid_Pressure_Monitoring.htm. Diakses pada tanggal 5 April 2014

27. Anderson R. Principles and Practice of Pediatric Neurosurgery. Treatment of Hydrocephalus with Shunt; Section II, Ch. 8. Thieme Medical Publisher, Inc. 2008;109-31. 